service but much teaching was done without cost to hospital or referring general practitioner. The problem is that other aspects of the university hospital's work previously funded in a general way out of SIFT would then be left unfunded unless additional resources were found.

What structure of funding would help to guarantee the future of medical education, research, and development in the NHS? How can we be sure to continue to attract many of the best brains into health care and use them to the full? Can we deny that while university hospitals surely must submit to strict managerial, medical, and educational audit (much of which they have themselves devised) their true success will never be measurable in commercial terms, that medical knowledge and development will be constrained in a market where cost effectiveness is the touchstone? Are we really prepared to see medical education and science jeopardised by the uncertain outcome of a market environment aimed at solving completely different problems?

There is no reason to doubt the sincerity and truth of $\mathrm{Mr}$ Clarke's statement on 10 July 1989 that "The comprehensive and high quality health service which will be needed to face the demands and challenges of tomorrow's world will depend crucially on the standard of medical education we provide and the range and quality of the nation's medical research programmes. Both are an intrinsic part of our commitment to the NHS" (speech to doctors in London).

We believe that the solution is to accept that it is in the national interest to have a small number of institutions whose special task it is to set the highest standards of care, to advance knowledge, and to inspire future doctors to excellence in a rapidly changing world, sending them out to every part of Britain once qualified with these models of care before them; and further, to accept that excellence is costly and must be funded, managed, and assessed in its own right but is at the same time a key component of care in the inner cities. This requires direct funding of the main university teaching hospitals by the Department of Health with a managerial mandate similar to that of the existing special health authorities but with the crucial difference that the undergraduate teaching hospitals continue to serve their locality as well as the country at large. Direct funding will not solve all the problems but it will greatly simplify the administrative process, stabilise the financial base, and allow time, energy, and imagination to be concentrated on the fundamental educational challenge, which has long been submerged in other pressures.

PETER RICHARDS

Dean,

St Mary's Hospital Medical School,

London W2 1PY

1 Roval Commission on University Education in London. Final report. London: HMSO, 1913.
Since Oppenheim introduced the term dystonia in 1911 it has had a rocky ride. ${ }^{1}$ The initial argument was whether dystonia was a neurological disease or was due to psychological distress. This seemed to be resolved when Herz resurrected the entity in $1944,{ }^{2}$ but instead the debate continued. Until the 1970 s most patients with dystonia were referred to psychiatrists in the belief that these curious motor disorders were an expression of an unhappy mind. Vigorous efforts over the past two decades have now, however, established that the various syndromes of dystonia are the result of abnormal brain function, usually in the basal ganglia. A cause for these movement disorders can be identified by modern investigation in about a quarter of cases; inheritance plays an important part in the remainder. Effective treatment can bé offered to most patients with this common disorder. ${ }^{34}$

\section{What is dystonia?}

Dystonia is a syndrome of sustained muscle contractions, frequently causing twisting and repetitive movements or abnormal postures. ${ }^{3}$ It can affect virtually any part of the body, and there are familiar names for dystonia at many different sites (box and figures 1-4). Typically, it starts in one part of the body as a focal dystonia. All dystonic movements and postures are worsened by attempts to move (action dystonia): to begin with they may appear only during a specific motor act, other movements being spared. If the syndrome is progressive (as is common in children but rare in adults) the initial action dystonia becomes apparent at rest and then spreads to affect other parts of the body (as segmental or multifocal dystonia); if progression continues dystonia may affect most or virtually all of the body (generalised dystonia).

Prolonged muscle contractions are the hallmark of dystonia; often they twist the body into characteristic postures. If continuous these spasms may cause constant twisted postures (except during deep stage three and four sleep and rapid eye movement sleep). If intermittent the spasms cause repetitive, often rhythmic jerks into dystonic postures - for example, the jerks of spasmodic torticollis. The shorter the spasms the more jerky or "myoclonic" is the dystonia. In addition, many patients with dystonia show true rhythmic tremors, either slow myorhythmias at about $3 \mathrm{~Hz}$ or faster tremors similar to those of benign essential tremor. Thus though dystonia is characterised by twisting spasms, it may also have additional myoclonic or tremulous components.

Age has a crucial but ill understood influence on the features of dystonia. The disease progresses to generalised or multifocal dystonia in some $60 \%$ of children (onset before the age of 13 years), in about $35 \%$ of adolescents (onset at 13-20), and in some $3 \%$ of adults (onset over the age of 20 ). Allied to this effect of age on the progression of dystonia is its effect on the site of onset. The legs are commonly affected first in children, less commonly in adolescents, and very rarely in adults. In summary, dystonia beginning in childhood usually 
Common names used to describe dystonia affecting specific parts of the body

Name

Muscles contracting involuntarily

Blepharospasm

Oromandibular dystonia

Lingual dystonia

Orbicularis oculi and neighbouring facial muscles

Jaw and mouth

Tongue

(Combination of blepharospasm and oromandibular and lingual dystonia is known as cranial dystonia, Meige's, or Brueghel's syndrome)

Spasmodic dysphonia

\section{Laryngeal, causing cord} adduction and a strangled speech, or cord adduction and whispering dysphonia

Dystonic dysphagia

Spasmodic torticollis

\section{Pharyngeal}

Sternocleidomastoid and posterior neck

(Combination of cranial dystonia and torticollis is known as craniocervical dystonia)

Writer's cramp and other occupational cramps

Axial dystonia

Hand, forearm, and arm

Back and trunk, causing scoliosis, lordosis, kyphosis, or tortipelvis

Leg dystonia

Foot, leg, and thigh

(Dystonia affecting only one part of the body (for example, spasmodic torticollis or dystonic writer's cramp) is known as a focal dystonia; if two or more adjacent parts (for example, torticollis with dystonic arms) as a segmental dystonia; two or more non-contiguous parts (for example, eyes, neck, and one leg) as multifocal dystonia; ipsilateral arm and leg as hemidystonia; and whole body, or most of it including legs, as generalised dystonia)

starts in the legs and progresses to become generalised or multifocal; in adults it starts in other body parts and usually remains focal (adult onset focal dystonia) or segmental; in adolescents progression is intermediate.

\section{What causes dystonia?}

Age affects the chances of identifying a cause for dystonia. Investigation will establish a pathological cause in about $40 \%$ of patients with an onset in childhood, in $30 \%$ of those with an onset in adolescence and in $13 \%$ or less of adults. ${ }^{5}$ These proportions are reflected in the success of investigation of different patterns of dystonia. A pathological cause is identified in about $45 \%$ of those with generalised or multifocal dystonia but in $10 \%$ or fewer of those with focal dystonias. Hemidystonia, however, is due to a structural cause in over $80 \%$ of cases - for example, a stroke, head injury, or brain tumour.

A huge range of hereditary metabolic, degenerative, and environmental conditions can present with dystonia; table I lists some of these. Such patients are said to have secondary or symptomatic dystonia. When no such cause is found the patient is said to have primary or idiopathic dystonia.

The syndrome of dystonia is recognised by clinical observation and examination of the patient presenting with a movement disorder. Once dystonia is recognised several questions need to be answered. Firstly, are there clinical clues to suggest that the dystonia is symptomatic? These clues are

FIG 1-Left hand is held in dystonic posture, as is left foot, which is internally rotated and plantar flexed with dystonic toes; right foot also is slightly inturned. FIG 2-Axial dystonia producing scoliosis and exaggerated lordosis. FIG 3-Focal dystonic writer's cramp: abnormal grip of pen between thumb and first finger and elevation of fourth finger. FIG 4-Blepharospasm (eyes are screwed up behind dark glasses), snarling of mouth, torticollis, and dystonic left arm
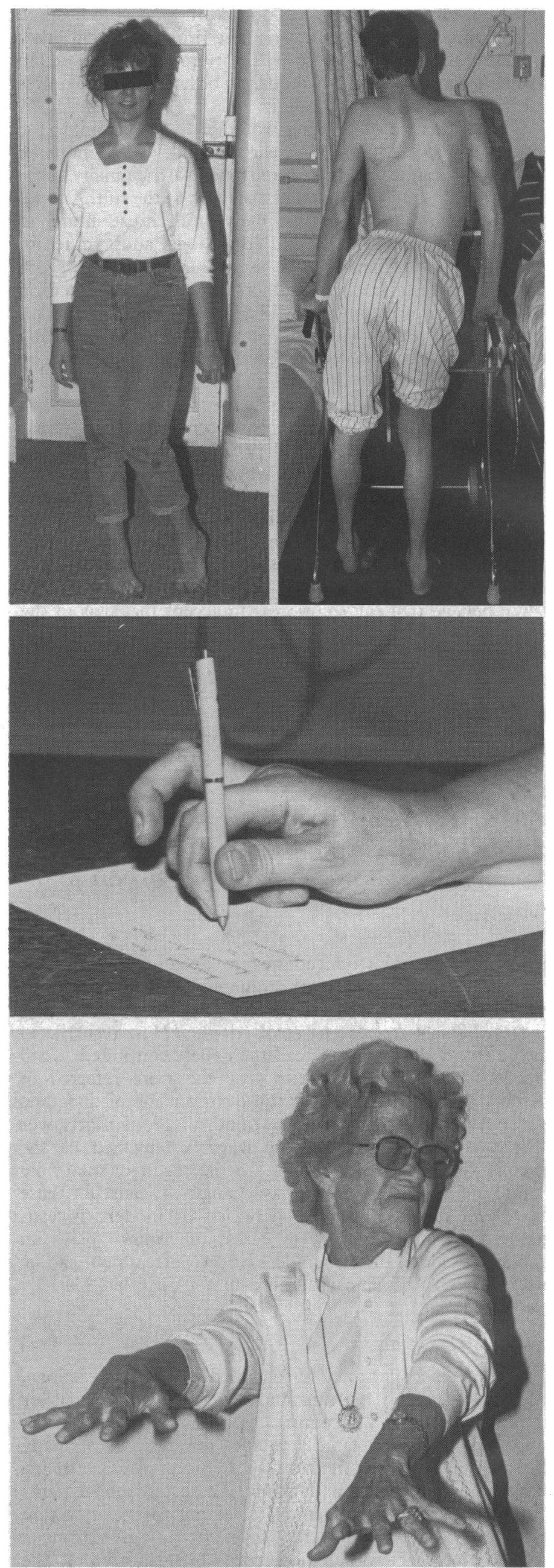

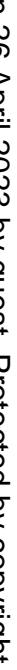


summarised in table II. Secondly, what further investigation is required? The investigations indicated in those clinically suspected of having idiopathic or symptomatic dystonia are shown in table III.

It is not appropriate to give details of the features of the many conditions that may cause dystonia or of the various investigations required, but a few comments are warranted. Wilson's disease, though rare, must be excluded in all patients with an onset of dystonia at or before age 50 because it is treatable - and without treatment it is fatal. Measurement of serum caeruloplasmin concentration and examination of the eyes with a slit lamp by an experienced observer are appropriate screening tests. If there is any doubt a liver biopsy is necessary to measure copper content of tissue. Imaging of the brain with computed tomography or, preferably, magnetic resonance imaging is a sensitive means of detecting structural lesions not only in hemidystonia due to stroke, head injury, or tumour but also in the metabolic or degenerative disorders that produce visible bilateral lesions in the basal ganglia.

\section{Idiopathic or primary dystonia}

In most patients with dystonia the clinical history and examination and simple investigations disclose no cause for the illness. Such patients have a normal birth and developmental history; no evidence of intellectual decline or seizures; and no signs of damage to pyramidal, cerebellar, sensory, visual, or eye movement pathways. They do not have Wilson's disease and have a normal brain scan on computed tomography or magnetic resonance imaging, or both.

In many patients with idiopathic dystonia, particularly with an onset in childhood and adolescence, the illness is inherited. Most cases of dystonia with an onset in adult life, however, occur sporadically.

A few distinct subcategories of inherited idiopathic dystonia have been teased out in recent years. Dystonia responsive to dopa accounts for some $5-10 \%$ of patients with inherited idiopathic dystonia. ${ }^{6}$ Inherited usually as an autosomal dominant trait, it starts in childhood or adolescence, usually with a disorder of gait. Many patients show diurnal fluctuations in the severity of their condition; they are

TABLE I - Some causes of symptomatic or secondary dystonia

\begin{tabular}{|c|c|c|}
\hline Metabolic disorders & $\begin{array}{c}\text { Other neurodegenerative } \\
\text { diseases }\end{array}$ & Other specific causes \\
\hline $\begin{array}{l}\text { Wilson's disease } \\
\text { Glutaric aciduria } \\
\text { Methylmalonic acidaemia } \\
\text { Homocystinuria } \\
\text { Metachromatic leucodystrophy } \\
\text { Pelizaeus-Merzbacher disease } \\
\mathrm{GM}_{1} \text { and } \mathrm{GM}_{2} \text { gangliosidoses } \\
\text { Ceroid lipofuscinosis } \\
\text { Juvenile dystonic lipidosis } \\
\text { Leigh disease } \\
\text { Mitochondrial } \\
\text { encephalomyopathy } \\
\text { Lesch-Nyhan syndrome }\end{array}$ & $\begin{array}{l}\text { Huntington's disease } \\
\text { Parkinson's disease } \\
\text { Steele-Richardson- } \\
\text { Olszewski disease } \\
\text { Multiple system atrophy } \\
\text { Progressive pallidal } \\
\text { degenerations } \\
\text { Hallervorden-Spatz disease } \\
\text { Neuroacanthocytosis } \\
\text { Ataxia telangiectasia } \\
\text { Familial basal ganglia } \\
\text { calcification }\end{array}$ & $\begin{array}{l}\text { Kernicterus } \\
\text { Perinatal brain injury } \\
\text { Viral encephalitis } \\
\text { Head trauma } \\
\text { Peripheral trauma } \\
\text { Stroke } \\
\text { Brain tumour } \\
\text { Arteriovenous malformation } \\
\text { Toxic exposure to manganese, } \\
\quad \text { carbon disulphide } \\
\text { Wasp sting } \\
\text { Side effects of drugs, such as } \\
\quad \text { neuroleptics, } \\
\text { antiparkinsonian agents }\end{array}$ \\
\hline
\end{tabular}

TABLE II-Clinical clues to symptomatic dystonia

\begin{tabular}{|c|c|c|}
\hline Clinical history & Neurological examination & Character of dystonia \\
\hline $\begin{array}{l}\text { Abnormal perinatal history } \\
\text { Delayed milestones } \\
\text { Precipitating illness } \\
\text { Seizures } \\
\text { Intellectual impairment } \\
\text { Defects of vision, hearing, or } \\
\text { sensation }\end{array}$ & $\begin{array}{l}\text { Abnormalities of eye } \\
\text { movements or optic fundi } \\
\text { Loss of postural reflexes } \\
\text { Pyramidal, cerebellar, or } \\
\text { sensory signs } \\
\text { Hepato-splenomegaly }\end{array}$ & $\begin{array}{l}\text { Fixed rather than mobile } \\
\text { dystonia } \\
\text { Hemidystonia at any age } \\
\text { Early involvement of speech in } \\
\text { children } \\
\text { Rapid progression or } \\
\text { generalised dystonia in } \\
\text { adults } \\
\text { Involvement of legs in adults }\end{array}$ \\
\hline
\end{tabular}

TABLE III-Investigations indicated in patients with dystonia suspected from clinical history and examination

\begin{tabular}{|c|c|c|c|}
\hline & \multicolumn{2}{|c|}{ Idiopathic dystonia } & \multirow[b]{2}{*}{$\begin{array}{l}\text { Symptomatic } \\
\text { dystonia } \\
\text { (onset at } \\
\text { any age) }\end{array}$} \\
\hline & $\begin{array}{l}\text { Onset in } \\
\text { childhood or } \\
\text { adolescence }\end{array}$ & $\begin{array}{c}\text { Onset in } \\
\text { adult life }\end{array}$ & \\
\hline \multicolumn{4}{|c|}{ Blood } \\
\hline Ceruloplasmin concentration & + & $t^{\star}$ & + \\
\hline Syphilis serology & + & + & + \\
\hline Blood count erythrocyte sedimentation rate & + & + & + \\
\hline Acanthocytes & + & & + \\
\hline Antinuclear antibodies & + & & + \\
\hline SMAC & + & + & + \\
\hline Creatine phosphokinase activity & & & + \\
\hline Uric acid concentration & & & + \\
\hline Amino acid concentration & & & + \\
\hline White cell lysomal enzymes & & & + \\
\hline $\begin{array}{l}\text { Hypoxanthine-guanine } \\
\text { phosphoribosyltransferase activity }\end{array}$ & & & + \\
\hline$\alpha$-fetoprotein concentration & & & + \\
\hline \multicolumn{4}{|l|}{ (1) } \\
\hline Amino acid concentration & & & + \\
\hline $24 \mathrm{~h}$ excretion of copper & & & + \\
\hline Oligosaccharide concentration & & & + \\
\hline Mucopolysaccharide concentration & & & + \\
\hline Organic acid concentration & & & + \\
\hline Examination of cerebrospinal fluid & + & & + \\
\hline \multicolumn{4}{|c|}{ Biopsy } \\
\hline Bone marrow & & & + \\
\hline Muscle & & & + \\
\hline Skin & & & + \\
\hline \multicolumn{4}{|c|}{ Other } \\
\hline Slit lamp examination of eyes & + & $+{ }^{\star}$ & + \\
\hline Computed tomography or magnetic & & & \\
\hline resonance imaging of brain & + & + & + \\
\hline Electromyopathy or nerve conduction & + & & + \\
\hline Electroencephalography & + & & + \\
\hline Electroretinography & & & + \\
\hline Evoked potentials & + & & + \\
\hline
\end{tabular}

† Segmental multiple analyser with computer.

less affected in the morning but deteriorate dramatically as the day wears on, particularly with exercise. Patients with this subcategory of idiopathic dystonia show a profound and sustained response to treatment with combinations of levodopa and either benserazide or carbidopa. Myoclonic dystonia sensitive to alcohol is also inherited as an autosomal dominant trait; it usually begins in early life with the combination of dystonia and fast, lightning-like myoclonic jerks. $^{7}$ A moderate dose of alcohol relieves the myoclonus but has less effect on the dystonia.

Usually dystonia is a continuous condition, but another subgroup of patients have attacks of paroxysmal dystonia, between which they are normal. Two varieties are recognised, both inherited as autosomal dominant traits with onset in early life ${ }^{8}$ Paroxysmal kinesigenic dystonia takes the form of brief (seconds to minutes) attacks of dystonia (or chorea) precipitated by sudden movement; such attacks occur many times each day. Consciousness is preserved in these episodes, which respond to treatment with anticonvulsant drugs such as phenytoin or carbamazepine. Paroxysmal non-kinesigenic dystonia refers to episodes of dystonia without loss of consciousness, not precipitated by movement, lasting longer (many minutes to hours), occurring much less frequently, and sometimes helped by clonazepam.

These subcategories of inherited idiopathic dystonia account together for a minority of patients. Most show no dramatic response to levodopa or alcohol and have continuous rather than paroxysmal dystonia. The mode of inheritance among this large group has been the subject of debate. At one time most were thought to have inherited the disorder as an autosomal recessive trait that is particularly common among the Ashkenazi Jews. Recent studies in the United States, Israel, ${ }^{10}$ and Britain ${ }^{11}$ have shown this view to be incorrect. A survey of 100 British families each containing an index patient with generalised, multifocal, or segmental dystonia showed 79 secondary cases (nearly half of whom were unaware they were affected). In about $85 \%$ of the patients the disorder was 
due to an autosomal dominant gene with about $40 \%$ penetrance and highly variable expression. There was no evidence for the existence of an autosomal recessive gene. There was a slightly higher number of Jewish patients than expected, but this was probably the result of a founder effect in eastern Europe. About $14 \%$ of these cases may have been new mutations. These data suggested that the estimated risk for children or siblings of familial cases developing clinical dystonia was $21 \%$; the risk to relatives of sporadic cases was lower, around $8-14 \%$.

These genetic data show that most patients with generalised, multifocal, or segmental idiopathic dystonia of onset in childhood or adolescence have an inherited disorder. The place of inheritance in adult onset focal dystonias is less clear. Most patients with isolated adult onset cranial dystonia, spasmodic torticollis, writer's cramp, and so on, do not report similarly affected family members, though occasional familial occurrence of all these disorders is well documented. Careful direct study of family members has not, however, been undertaken in these conditions. In the study in Britain of more widespread dystonia described above about half of secondary cases were asymptomatic, and many were unrecognised even among the family. "Such asymptomatic cases in otherwise obviously autosomal dominant pedigrees often took the form of isolated adult onset dystonia. It may turn out that inheritance plays a much larger part than is appreciated at present in the focal idiopathic dystonias of adult onset.

Despite intensive effort the gene (or genes) responsible for inherited idiopathic dystonia has yet to be identified.

\section{The pathophysiology of idiopathic dystonia}

The commonest lesions disclosed by brain scan with computed tomography or magnetic resonance imaging or by pathological examination in patients with symptomatic dystonia lie in the basal ganglia (particularly in the putamen). ${ }^{12}$ Drug induced dystonia is usually provoked by agents known to influence biochemical reactions in the basal ganglia; these include acute dystonic reactions or tardive dystonias produced by antipsychotic or neuroleptic drugs and dystonic dyskinesias induced by dopaminergic agents used to treat Parkinson's disease. This suggests that dysfunction of the basal ganglia is likely to be at the root of idiopathic dystonia, but so far no structural cause has been identified in this or any other region of the brain. Patients with idiopathic dystonia, whatever the age of onset, have normal brain scans on computed tomography or magnetic resonance imaging. The few who have come to necropsy usually have had "normal" brains on light microscopy. ${ }^{13}$ The presumption is that idio-

TABLE IV-Occurrence of dystonia and some other neurologic diseases

\begin{tabular}{|c|c|c|c|}
\hline & \multicolumn{3}{|c|}{ Prevalence per million } \\
\hline & $\begin{array}{l}\text { Idiopathic } \\
\text { dystonia }^{\star}\end{array}$ & $\begin{array}{c}\text { Symptomatic } \\
\text { dystonia }\end{array}$ & Total \\
\hline Generalised dystonia & 34 & 28 & 62 \\
\hline Focal dystonia: & 296 & 33 & 329 \\
\hline Cranial dystonia & 86 & & \\
\hline Spasmodic dysphonia & 52 & & \\
\hline Spasmodic torticollis & 89 & & \\
\hline W'riter's cramp & 69 & & \\
\hline All dystonias & 330 & 61 & $391 \ddagger$ \\
\hline Multiple sclerosis ${ }^{\star}$ & & & 600 \\
\hline Parkinson's disease ${ }^{\star}$ & & & 1000 \\
\hline Huntington's disease ${ }^{\star}$ & & & 67 \\
\hline Motor neurone disease ${ }^{\star}$ & & & 64 \\
\hline Muscular dystrophy ${ }^{\star}$ & & & 60 \\
\hline Myasthenia gravis` & & & 38 \\
\hline
\end{tabular}

${ }^{\star}$ Data from Rochester, Minnesota. ${ }^{1 \times 20}$

tCalculated on the basis that $45 \%$ of all cases of generalised dystonia and $10 \%$ of cases of focal dystonia are symptomatic.

$\ddagger$ This may be a substantial underestimate. pathic dystonia is due to some biochemical disturbance of activity of basal ganglia, but no consistent biochemical abnormality has been identified as yet. ${ }^{1+}$ More study is needed, both morphological and biochemical, of the brain in patients with dystonia.

Despite the failure so far to identify the brain abnormality responsible for dystonia neurophysiological clues are beginning to emerge. In blepharospasm the second component of the electrically induced blink reflex has been shown to be overexcitable $^{15}$; in torticollis there is failure of exteroceptive suppression of neck motorneurone activity ${ }^{16}$; and in arm dystonia (including writer's cramp) there is a loss of the second interneuronal phase at reciprocal inhibition. ${ }^{17}$ Electrophysiological studies of this kind have shown the various forms of dystonia to have a true neurological substrate; they can no longer be considered "psychogenic" conditions. They also point to the conclusion that actions of brainstem and spinal interneurones concerned with reciprocal and other inhibition of unwanted motor activity are defective in dystonia, perhaps owing to distorted descending basal ganglia drive.

\section{How common is dystonia?}

Most practitioners consider dystonia to be rare, but this is not true. Few epidemiological studies have been carried out, in part as a result of the fairly recent recognition that this is a neurological disease. The best guess as to its prevalence is based upon a survey of cases at the Mayo Clinic from the records of people residing within the city limits of Rochester, Minnesota. ${ }^{18}$ The prevalence of diagnosed idiopathic generalised dystonia within this community was estimated at 34 per million and of the various idiopathic focal dystonias at 294 per million (table IV). Assuming an additional $45 \%$ of cases of symptomatic generalised dystonia and $10 \%$ of cases of symptomatic focal dystonia, the total prevalence of all forms of dystonia might be 391 per million. This is approaching three quarters of the prevalence of multiple sclerosis. Within Britain there may be $4000-5000$ patients with blepharospasm or cranial dystonia, a slightly larger number with spasmodic torticollis, 2000-3000 with spasmodic dysphonia, 3000-4000 with writer's cramp, and 3000-4000 with generalised dystonia; overall, there may be more than 20000 people with all types of dystonia. If we remember, however, that in the genetic survey of dystonia in Britain about half of secondary cases were asymptomatic this may be a large underestimate. Dystonia is, then, far more common than many other well known neurological diseases such as Huntington's disease, motor neurone disease, or myasthenia gravis.

\section{Drug treatment of dystonia}

There are no cures for most types of dystonia. One of the spectacular advances in neurology in recent years, however, has been the development of effective treatment of symptoms for many patients. Foremost have been treatment with high doses of anticholinergic drugs for childhood and adolescent generalised, multifocal, or segmental dystonia and treatment with injection of botulinum toxin for various focal dystonias.

Before discussion of drug treatment the possibility of spontaneous remission should be considered. About one in 20 of patients with any form of idiopathic dystonia may experience a spontaneous improvement or even resolution of their movement disorder. This is most likely in the first five years of the illness, and subsequent relapses are common. Some patients, however, continue with a prolonged remission for years or decades. In idiopathic childhood or adolescent onset dystonia maximum progression tends to occur in the 
first five years of the illness; less deterioration occurs in the next five years, and once adult life is reached the condition tends to stabilise or to progress only slightly. The lack of progression in most of those with adult onset idiopathic focal dystonia has been emphasised earlier.

Many drugs have been reported to be of some benefit in some patients, but two are important: levodopa preparations and anticholinergic agents. All children and adolescents presenting with dystonia, particularly if it starts in the legs, should first be given a trial of levodopa to see if they have dopa responsive dystonia. ${ }^{6}$ Combinations with a dopa decarboxylase inhibitor may be used; carbidopa is preferable in women who may wish to become pregnant. We use $100 \mathrm{~g}$ levodopa with $25 \mathrm{mg}$ carbidopa, building up to two tablets three times a day for three months. If there is no useful response in that time the drug is withdrawn. If there is a benefit it is usually dramatic and will then be sustained for as long as the drug is taken - 10 years or more in some cases. In general, these patients do not run into the long term problems of treatment with levodopa that are so common in Parkinson's disease.

For children and adolescents who fail to respond to levodopa the next choice is an anticholinergic drug such as benzhexol (known in the United States as trihexyphenidyl). The trick is to start with small doses (benzhexol $2.5 \mathrm{mg}$ twice a day) and then increase slowly - by an extra $2.5 \mathrm{mg}$ a day every one to two weeks - up to the maximum the patient can tolerate. Such a very slow introduction minimises side effects, but sooner or later these intrude to limit dosage. They consist of peripheral problems such as a dry mouth, blurred vision, urinary hesitancy, anorexia and weight loss, and central adverse effects, such as forgetfulness, confusion, behavioural change, hallucinations, and chorea. Nevertheless, young patients seem to tolerate high doses (occasionally up to $180 \mathrm{mg}$ a day) remarkably well. General experience indicates that about half of children and adolescents benefit, sometimes spectacularly. ${ }^{+}$Despite the very high doses of anticholinergic drugs used no long term problems have emerged in the eight to 15 years of use.

Adults tolerate anticholinergic drugs less well than children and adolescents; central adverse effects are more common and high doses often cannot be achieved. Only about a fifth of patients with adult onset focal dystonia benefit from anticholinergic drugs. How these high doses of anticholinergic agents benefit patients with dystonia is unknown. Why such large doses may be required (40-120 mg benzhexol daily is commonly necessary), and why it may take weeks or months of treatment before improvement occurs are mysteries.

In patients who fail to respond to levodopa or high dose anticholinergic treatment other agents may be used. ${ }^{+}$Many benefit from benzodiazepines, such as diazepam, often in high dosage, which seem to relax dystonic spasms. A few have responded to high dose baclofen, and even fewer to carbamazepine. Dopamine receptor antagonists or neuroleptics such as phenothiazines, haloperidol, or pimozide are also sometimes useful. Often they act non-specifically, damping down excessive movements by causing a degree of drug induced parkinsonism; there also is the risk of adding a tardive dyskinesia to the dystonia. Tetrabenazine, which depletes the brain of dopamine, carries less risk of inducing a tardive dyskinesia but may cause depression. For those with very severe dystonia it may be necessary to combine drugs to gain some control of the muscle spasms. One combination which sometimes is effective is a low dose of tetrabenazine (25 mg three times a day) with pimozide (in gradually increasing doses up to $12 \mathrm{mg}$ daily) and benzhexol (gradually increasing to the maximum tolerable).

Patients with adult onset focal dystonias usually do not respond to drug treatment, or they develop intolerable side effects. The advent of botulinum toxin has given welcome relief to many with blepharospasm, spasmodic torticollis, and spasmodic dysphonia. Botulinum toxin acts presynaptically, after being taken up into peripheral nerve terminals, to prevent calcium dependent release of acetylcholine. Local injections of small doses of botulinum toxin A into affected muscles cause the development of weakness over the next week or so, thereby reducing or abolishing the dystonic spasms. The effect lasts some two to four months, then wears off as terminal sprouting restores muscle end plate neurotransmission. No serious systemic adverse effects have been recorded, and repeated injections have continued to give benefit over the eight or so years the treatment has been in use. Theoretical problems, such as systemic weakness due to widespread distribution of the toxin and the development of antibodies to botulinum toxin, have not yet proved to be practical difficulties. So far injections of the toxin have proved to be safe and effective.

Injection of botulinum toxin into the periorbital muscles is now the best treatment for disabling blepharospasm. ${ }^{21}$ Some $70-80 \%$ of patients can expect a return of useful vision from previous functional blindness. Lower facial spasms may also be improved in some patients, in whom they may be a compensatory attempt to open the eyes, but more commonly oromandibular dystonia is a spread of the dystonic process. Local swelling and bruising and a mild ptosis resolving over two to three weeks occur in about a quarter of patients. More severe ptosis and diplopia, again transient, occur in about $5 \%$ of patients. Those who fail to benefit may have additional problems such as levator inhibition (inability to voluntarily raise the eyelids) or recurrent spontaneous Bell's phenomenon (in which the eyeballs roll up behind the eyelids), which may interfere with vision. Others may have local mechanical problems caused by longstanding blepharospasm, such as levator disinsertion, overhanging eyebrows, or excess eyelid tissue, which may require local oculoplastic surgery.

Injections of botulinum toxin into the appropriate neck muscles (for example, for pure rotational torticollis into the contralateral sternocleidomastoid and ipsilateral splenius) are also emerging as the best treatment for spasmodic torticollis. ${ }^{22}$ Some $70 \%$ of patients are improved, with a straighter head and better head control, and $90 \%$ have relief or lessening of pain of the neck. The anterior injection into sternocleidomastoid may diffuse to the larynx and pharynx to cause weakening of the voice and difficulty in swallowing in about $10 \%$ of patients; this is transient, resolving in about two to three weeks, and has not proved to be an important problem. Patients with retrocollis may also benefit from bilateral posterior injections into splenius, and the raised shoulder so often present in torticollis may require an injection into the upper fibres of trapezius. Antecollis, tremulous torticollis, and variable torticollis are more difficult to treat with botulinum toxin and may require prior electromyographic investigation to establish the best sites of injection.

More recently the toxin has been used successfully to treat spasmodic dysphonia due to dystonic contraction of the vocal cord adductor muscles. ${ }^{23}$ It is injected into one or both of these muscles (whether unilateral or bilateral injections give the best results is not yet clear) through electromyographic needles used to localise the muscles accurately. A fairly normal voice can be achieved in most patients who have the strangled low volume speech of spasmodic dysphonia.

Botulinum toxin is also being investigated as a treatment for writer's cramp and other occupational dystonias. ${ }^{24}$ Injections into the specific finger muscles affected, as identified by electromyographic studies, may prove beneficial, though the 
technique is more complicated than that for blepharospasm, spasmodic torticollis, and spasmodic dysphonia.

The toxin is also being used to help other dystonic problems. Injections into the temporalis and masseter muscles may benefit those with jaw closing spasms; injection into the ptyerigoids are needed for the jaw opening spasms of oromandibular dystonia. Injection into the finger flexor muscles in the forearm may open a dystonic hand; injections into calf muscles may allow a dystonic foot to gain a plantar grade position; injection into thigh muscles may help spasms around the hip and knee; and injections into the abdomen and back may benefit some patients with axial dystonia. The development of these applications of the toxin is occurring rapidly and offers help with symptoms for many other patients with dystonia.

The use of botulinum toxin in dystonia has been so successful that every regional neuroscience centre needs to provide this skill to cope with the clinical need.

\section{Other treatments}

As is inevitable with any chronic disabling condition, patients try many other forms of treatment. Physiotherapy is of great benefit in preventing dystonic muscles developing contractures (which are rare) but cannot yet teach the brain to deliver normal motor programmes. Mechanical braces are largely useless; the dystonic spasms often fight the constraint, sometimes breaking it or injuring the skin. They sometimes help, however, not by constraining the affected part, but by acting as a "geste antagoniste." Intelligent assessment and use of aids to mobility and communication are essential for those who are severely disabled. Supportive psychotherapy is important, and formal psychiatric treatment may be required for any secondary depressive illness. Hypnotherapy, relaxation, acupuncture, homoeopathy, biofeedback, chiropractic treatment, and so on, have little to offer dystonic patients.

Before the advent of botulinum toxin surgery was used to try to help dystonic patients, usually with limited success. Facial nerve section for blepharospasm is now reserved for those who fail to gain adequate benefit from treatment with toxin. Peripheral nerve or root section for torticollis is rarely

1 Oppenheim H. Uber eine eigenartige Krampfkrankheit des kindlichen und jugendlichen Alters (dysbasia lordotica progressiva, dystonia musculorum deformans). Neurologie Centralblat 1911;30:1090-107.

2 Herz E. Dystonia I. Historical review: analysis of dystonic symptoms and physiologic mechanisms involved. Archives of Neurology and Psychiatry 1944;51:305-18

3 Fahn S, Marsden CD, Calne DB. Classification and investigation of dystonia. In: Marsden CD, Fahn S, eds. Movement disorders 2. London: Butterworth, 1987:332-58.

4 Fahn S, Marsden CD. The treatment of dystonia. In: Marsden CD, Fahn S, eds. Movement disorders 2. London: Butterworth, 1987:359-82.

5 Marsden CD. Investigation of dystonia. Adv Neurol 1988:50:35-44.

6 Nygaard TG, Marsden CD, Duvoisin RC. Dopa-responsive dystonia. Adv Neurol 1988;50:377-84.

7 Quinn NP, Rothwell JC, Thompson PD, Marsden CD. Hereditary myoclonic dystonia, hereditary torsion dystonia and hereditary essential myoclonus: an area of confusion. Adv Neuro 1988;50:391-401.

8 Lance JW. Familial paroxysmal dystonic choreoathetosis and its differentiation from related syndromes. Ann Neurol 1977;2:285-93.

9 Bressman SB, de Leon D, Brin MF, et al. Inheritance of idiopathic torsion dystonia among Ashkenazi Jews. Adv Neurol 1988:50:45-56.

10 Zilber N, Korczyn AD, Kahana E, Fried K, Alter M. Inheritance of idiopathic torsion dystonia amongst Jews. F Med Genet 1984;21:13-20.

11 Fletcher NA, Harding AE, Marsden CD. A genetic study of idiopathic torsion dystonia in the UK. Brain (in press).

12 Marsden CD, Obeso JA, Zarranz JJ, Lang AE. The anatomical basis of symptomatic hemidystonia Brain 1985; 108:463-83.

13 Zweig RM, Hedreen JC, Jankel WR, Casanova MF, Whitehouse PJ, Price DL. Pathology in brainstem regions of individuals with primary dystonia. Neurology 1988;38:702-6. indicated now. Thalamotomy for stable hemidystonia is still useful, but bilateral thalamotomy for generalised dystonia is only rarely used, in part because of the risk of compromising speech. Cervical cord stimulation has proved to be disappointing in dystonia.

\section{Conclusions}

Dystonia in its various forms has emerged as a common neurological illness. Clinicians need to recognise the manifestations of dystonia and to appreciate that they are due to brain disease not psychopathology. Specialised investigations can now establish a cause in some patients with dystonic syndromes, particularly in younger patients. In those with idiopathic dystonia inheritance plays an important part in what is probably a heterogeneous condition. Recently linkage studies using a complementary DNA probe for the gelsolin locus have identified the definitive gene in a large North American family with autosomal dominant dystonia to be on chromosome 9q. ${ }^{25}$ How the gene(s) for dystonia causes brain dysfunction is not known. Brain (and spinal cord) material from patients with dystonia is urgently required for study. Effective treatment for dystonia is now available for many patients; drug treatment in young patients (with levodopa or anticholinergic agents) offers considerable hope of benefit. Botulinum toxin injections can relieve focal dystonias, and this is emerging as the best treatment for many adult onset focal dystonias such as blepharospasm, spasmodic torticollis, and spasmodic dysphonia.

A vigorous lay society - the Dystonia Society (Unit 32, Omnibus Workspace, 39-41 North Road, London N7 9DP, tel 017004594 ) has been formed to provide information, counselling, support groups, and a brain donation scheme.

C D MARSDEN Professor of Neurology

N P QUINN

Lecturer in Clinical Neurology

Institute of Neurology,

The National Hospitals for Nervous Diseases,

London WCIN 3BG
14 Hornykiewicz O, Kish SJ, Becker LE, Farley I, Shannak K. Brain neurotransmitters in dystonia musculorum deformans. N Engl f Med 1986;315:347-53.

5 Berardelli A, Rothwell JC, Day BL, Marsden CD. Pathophysiology of blepharospasm and oromandibular dystonias. Brain 1985;108:593-608

16 Nakashima K, Thompson PD, Rothwell JC, Day BL, Stell R, Marsden CD. An exteroceptive reflex in the sternocleidomastoid muscle produced by electrical stimulation of the supraorbital nerve in normal subjects and patients with spasmodic torticollis. Neurology 1989;39:1354-8.

17 Nakashima K, Rothwell JC, Day BL, Thompson PD, Shannon K, Marsden CD. Reciprocal inhibition between forearm muscles in patients with writer's cramp and other occupational cramps, symptomatic hemidystonia and hemiparesis due to stroke. Brain 1989;112:681-97.

18 Nutt JG, Muenter MD, Aronson A, Kurland LT, Melton LJ. Epidemiology of focal and generalised dystonia in Rochester, Minnesota. Movement Disorders 1988;3:188-94.

19 Percy AK, Nobrega FT, Okazaki H, Glattre E, Kurland LT. Multiple sclerosis in Rochester, Minnesota - a 60-year appraisal. Arch Neurol 1971;25:105-11.
Mercy AK, Nobrega FT, Okazaki H, Glatre E, Kurland LT

20 Nobrega FT, Glattre E, Kurland LT, Okazaki H. Genetics and epidemiology of Parkinson's disease. In: Barbeau A, Brunette JR, eds. Progress in neurogenetics. Amsterdam: Excerpta Medica, 1967:474-85.

21 Grandas F, Elston J, Quinn N, Marsden CD. Blepharospasm: a review of 264 patients. 7 Neurol Neurosurg Psychiatry 1988;51:767-72.

22 Stell R, Thompson PD, Marsden CD. Botulinum toxin in spasmodic torticollis. $\mathcal{f}$ Neurol Neurosurg Psychiatry 1988;51:920-3.

23 Ludlow CL, Naunton RF, Sedory SE, Schulz GM, Hallett M. Effects of botulinum toxin injections on speech in adductor spasmodic dysphonia. Neurology 1988;38:1220-5.

24 Cohen LG, Hallett M, Geller BD, Hochberg F. Treatment of focal dystonias of the hand with botulinum toxin injections. $\mathcal{F}$ Neurol Neurosurg Psychiatry 1989;52:355-63.

25 Ozelins L, Kramer PL, Moskowitz CR. Human gene for torsion dystonia located on chromosome 9q32-q34. Neuron 1989;2:1427-34. 